Journal of Economics and Behavioral Studies

Vol. 6, No. 11, pp. 868-873, November 2014 (ISSN: 2220-6140)

\title{
Farmer Perceptions and Demand for Pesticide Use: A Case Study of Rice Production in the Mekong Delta, Vietnam
}

\author{
Huynh Viet Khai \\ School of Economics and Business Administration, Can Tho University, Vietnam \\ hvkhai@ctu.edu.vn
}

\begin{abstract}
Rice farmers' perceptions and demand for pesticide use were analyzed using survey data in the Mekong Delta of Vietnam. The study showed although the majority of farmers could recognize the harmful effects of pesticides, they did not wear protective clothing suggested by WHO for pesticide safety use because they did not feel comfortable to use under local climatic conditions. Most of farmers declared that they asked for information or instructions related to pesticide use and pest prevention from retailers (72.5 percent) and over half of them (52.5 percent) sold their pesticide empty packages. The study also investigated that an increase in output price or farmers who thought an increasing tendency of insects and diseases had positive impacts on pesticides, while farmers who had knowledge on natural enemies or took part in short trainings or workshops applied less pesticides than others.
\end{abstract}

Keywords: Attitudes, pesticide demand, pesticide hazards, pest management, farmers' awareness

\section{Introduction}

Traditional vegetable farming systems without any chemical inputs cannot meet the increasing vegetable demand of urban residents in Vietnam. One of the reasons is due to the increasing development of pests and diseases in vegetable production. So requiring pest management effectively to increase the amount of producing vegetables can satisfy a large demand for vegetables in the urban market. Use of chemical pesticides is one of the popular and effective ways to control the pests and diseases in vegetable production in Vietnam. However, besides the benefits that it brings, pesticides potentially affect the health of users and the surrounding environment. If not used properly, pesticides cause human poisoning and is accumulated as residues in food and the environment, which result in the variety of human diseases. Excessive pesticide usage can also lead to the development of resistant strains of pests. There have been a number of studies related to farmers' attitudes or perceptions of pesticide use in the developing countries. Rahman (2003) used the data surveyed in 21 villages of Bangladesh to analyze awareness of beneficial and harmful effects of pesticides and factors determining the use of pesticides. The study found that pesticide costs accounted for between 1 percent and 7.7 percent of total gross output value depending on the various crops. The positive effect of fertilizer prices and pesticide use indicated that farmers considered pesticides as substitutes for fertilizers. Land ownership and agricultural credit had positively impacted on pesticide use. The study by Bhanti et al. (2004) indicated that Indian farmers had enough understanding of the dangers of the term 'acute pesticide poisoning' but lack awareness of the long-term chronic risk of pesticide use.

Ntow et al. (2006) surveyed 137 farmers to analyze farmers' perceptions of pesticide usage in vegetable cultivation in Ghana. The study performed that various inappropriate practices in the handling and use of pesticides caused possible poisoning symptoms among those farmers who generally did not wear protective clothing. Younger farmers were the most pesticides-effected group and well-targeted training programs related to the safe use of pesticides was recommended. The study by Waichman et al. (2007) discovered that the information displayed on product labels was not effective in promoting protective and safe measures for farmers in Brazil, while Ngowi et al. (2007) investigated that vegetable farmers in Tanzania were lack of appropriate knowledge on safe handling and use of pesticides and Oo et al. (2012) found although almost all farmers in Inlay Lake of Myanmar had known the negative impact of pesticides on their health, only 86.9 of them always used protective things during pesticide spraying. Since farmer's perception and use of pesticides have not received much attention, up to now there is little information on this topic in the peerreviewed literature in Vietnam. Berg (2001) surveyed rice and rice-fish farmers in the Mekong Delta to 
analyze their perceptions about pest management practices. The study showed that Non- Integrated Pest Management (IPM) farmers used twice as many pesticides as IPM farmers and integrating rice-fish farming with IPM practices was a sustainable alternative to intensive rice mono-cropping in terms of an economic and an ecological point of view. Van Mele et al. (2001) investigated that the pesticide spray load of mango farmers in the Vietnamese Mekong Delta increased from 26 to 37 sprays per year due to pesticide sellers' suggests, while the application of insecticide products increased from 2.6 to 3.9 per farmer recommended by extension staff and media.

A Study on the perceptions of pesticide use, especially pesticide risks to human health, is very important and necessary because it provides information on the effects of farmers' decisions on the amount and methods of pesticide usage, and the health problems that farmers might deal with if their pesticide use and crop protection are inappropriate and irrelevant (Ntow et al., 2006).Beside the limited information about farmer perceptions and pesticide use practices provided by previous studies, the aim of this study is to provide more pictures of farmers' awareness of beneficial and harmful effects of pesticides, and to analyze the demand of pesticides and identify factors affecting pesticide usagein the Mekong Delta, Vietnam. The study provides policy makers and concerned people more useful information about farmers' attitudes toward pesticide usage and hazards to issue and implicate appreciate pesticide policies and issues. The paper is structured as follows. The next section describes the way to collect and analyze the pesticide data. The following section reports the results and some important discussions about farmers' perceptions and demand of pesticide use. The final section presents the conclusions and proposes some useful recommendations.

\section{Materials and methods}

Data collection: Primary data were conducted by randomly interviewing rice farmers in the Giong Rieng district of KienGiang province located in the Mekong Delta, Vietnam. GiongRieng district is one of the largest rice producing areas of KienGiang province, in which most farmers cultivated rice as their main earnings. Almost all of them use pesticides mainly for increasing productivity to get more income and improve their life, but do not pay much attention to the negative effects of pesticides. The structure or design of the survey was divided into three main steps. Firstly, comments and consultants from local experts and officers at the Department of Agriculture and Rural Development in GiangRieng were received to form the questionnaire. Secondly, the pilot surveying and pretesting is conducted to refine the questionnaire and finally the final revised questionnaire was used to collect a total of 80 rice farmers from three villages (Ngoc Thanh, Ngoc Thuan, Thanh Hung) in the study site. The collected data were analyzed by the statistical software Stata version 11 .

Econometric model: The study applied a model based on farmers' profit maximizing behavior to identify the demand of pesticides. To make it simple, the study assumes that there are two input vectors including the vector of pesticides $(Q)$ and the vector of other inputs $(Z)$ to produce rice with the amount of output $(Y)$. The objective of an individual rice farmer is to maximize the following total profit $(\pi)$ :

$$
\begin{aligned}
& \pi=\left(p Y-w_{Q} Q-w_{Z} Z\right) \rightarrow \max \\
& \text { s.t. } Y=f(Q, Z, A, S)
\end{aligned}
$$

where the equation (2) is the production function of an individual rice farmer, which depends on the amount of pesticide use, other inputs applied, and land $(A)$ allocated to rice cultivation; $p$ and $w$ are the output price and input prices, respectively and $S$ presents the vector of socio-economic characteristic variables. The first order condition results in the pesticide demand function of rice production as follows:

$$
Q=Q\left(w_{Q}, w_{z}, p, A, S\right)
$$

According to Rahman (2003), the pesticide demand function can be identified by observable independent factors such as the input prices, output price and exogenous variables. The specific function form is presented as follows:

$$
\ln (Q)=\beta_{1}+\beta_{2} \ln (W)+\beta_{3} \ln (P)+\beta_{4} \ln (A)+\sum_{k=5}^{9} \beta_{k} z_{k}+u
$$

where $Q$ is the total amount of pesticides use $\left(\mathrm{ml} / 1000 \mathrm{~m}^{2}\right), W$ is the price of pesticides $(\mathrm{VND} / \mathrm{ml}), P$ is the output price of rice $(\mathrm{VND} / \mathrm{kg}), A$ is the area of rice cultivated land $\left(1000 \mathrm{~m}^{2}\right)$, and $\mathrm{Z}_{\mathrm{k}}$ is a set of socio-economic characteristic including education level of farmers (years) (5), pesticide experience (years) (6), Knowledge on 
pesticide use (scores) (7), knowledge on pet insect (8), and farmers' perception on insect trend (9). $u$ is the error term of the function.

\section{Results and discussion}

Perceptions and pesticide use practices of rice famers: Table 1 performs the situation of pesticide use of rice farmers. One of the most important sources of pesticide information is the label of pesticides, giving all relevant information on the safety of pesticide use and environmental and health risk reduction (Waichman et al., 2007). The study performs that almost all farmers (78.8 percent) always read the instructions on pesticide labels before spraying and only 16 farmers ( 20 percent of the sample) declare sometimes to read product labels.

Table 1: Overview of pesticide usage of rice farmers

\begin{tabular}{|c|c|c|c|c|c|c|}
\hline & \multicolumn{2}{|c|}{ Never } & \multicolumn{2}{|c|}{ Sometime } & \multicolumn{2}{|c|}{ Always } \\
\hline & $N$ & $\%$ & $N$ & $\%$ & $N$ & $\%$ \\
\hline Reading pesticide labels before using & 1 & 1.3 & 16 & 20.0 & 63 & 78.8 \\
\hline Mixing pesticides more than one & 8 & 10.0 & 62 & 77.5 & 10 & 12.5 \\
\hline Mixing pesticides using by hand & 57 & 71.3 & 16 & 20.0 & 7 & 8.8 \\
\hline Wearing protective things & 9 & 11.3 & 22 & 27.5 & 49 & 61.3 \\
\hline Waiting for $12 \mathrm{~h}$ after spraying pesticides to go to fields & 3 & 3.8 & 21 & 26.3 & 56 & 70.0 \\
\hline Keeping locked away and out of reach of children & 0 & 0.0 & 15 & 18.8 & 65 & 81.3 \\
\hline Keeping pesticides in safety places & 1 & 1.3 & 18 & 22.5 & 61 & 76.3 \\
\hline Bathing after application & 1 & 1.3 & 18 & 22.5 & 61 & 76.3 \\
\hline
\end{tabular}

Source: Own estimates; data appendix available from authors.

Table 2: Information sources, store places of pesticide use and fate of empty packages

\begin{tabular}{lcc}
\hline & Number & Percent (\%) \\
\hline Source & 17 & 21.3 \\
Pesticide label & 20 & 25.0 \\
Technician & 49 & 61.3 \\
Own experience & 32 & 40.0 \\
Other farmer & 58 & 72.5 \\
Retailer & & \\
Place for pesticide storage & 32 & 40.0 \\
In the bedroom & 17 & 21.3 \\
In the desk & 18 & 22.5 \\
Inside the storage area & 13 & 16.3 \\
In the field & & \\
Fate of empty packages & 42 & 52.5 \\
Sold & 13 & 16.3 \\
Kept for other uses & 22 & 27.5 \\
Discarded into the river, field & 3 & 3.8 \\
Buried
\end{tabular}

Source: Own estimates; data appendix available from authors.

The pesticide strategic management does not recommend using a combination of various pesticides at the same time that may lead an increase in the pest resistance. The study finds out most of the farmers said that they sometime (77.5 percent) or always (12.5 percent) mixed different pesticides together while only 10 percent those who never applied more than one kind of pesticides at the same time. When farmers were interviewed whether or not they used their hands to mix pesticides for using, about 29 percent of them replied that they at least one time mixed pesticides by hand. Unlike other developing countries, this study shows Vietnamese farmers have gradually recognized the danger or hazard of pesticides. They try their best to reduce the negative effects on their own or family health. Over half of respondents (61.3 percent) declare 
that they always wear protective equipment, while only 9 farmers (11.3 percent) in the sample said that they have never used any protective things during the time of pesticide spraying. However, their protective things are mainly masks and goggles that are so simple and not full enough to protect their health and none of them wear protective clothing recommended by WHO for the safety usage of pesticides because they consider too uncomfortable to use under local climatic conditions. Most of them always keep pesticides out of reach of children (81.3 percent), always store chemical materials in safe places (76.8 percent) and claim that they always wait12 hours after pesticide spraying to carry on working as normal in the field ( 70 percent). About 76 percent of farmers claim that they always take a bath after pesticide spraying.

Table 2 reports the places where farmers receive information on chemical usage, store pesticides and put empty packages. Regarding the safety use of pesticides, the knowledge and information on pest prevention are very important for rice farmers. The study shows that only 21.3 percent of rice farmers read the instructions displayed on the labels for using pesticide safety. The majority of them (72.5 percent) ask for information on pesticide use from retailers and on their own experience (61.3 percent), while only 25 percent of the farmers receive knowledge on pesticide usage from technicians. However, most of the technicians are from pesticide companies and few from government agricultural extension services, revealing that the extension services, short trainings given by local governments are limited or do not work so well in the study area. Most of farmers store pesticides in their homes, including 40 percent in the bedroom and 21.3 percent inside the desk. This practice could increase the risk of accidental poisoning by family members. When farmers were asked about the disposal of pesticide empty containers, about 52.5 percent of them declared to sell pesticide empty packages and over 16 percent washed them for other uses. This is very dangerous if the containers that were not washed clean enough have negative impacts on the health of farmers. Another inadequate practice of container disposal discarded into the rivers and fields is reported by 27.5 percent of farmers, while very few (3.8 percent) buries empty packages into the ground.

Estimation of rice farmers' demand for pesticides: Table 3 performs that descriptive statistics of related variables used in the demand function of pesticides. Rice farmers use pesticide with the average amount of $450 \mathrm{ml}$ per $1000 \mathrm{~m} 2$ and the mean price of $1,000 \mathrm{VND} / \mathrm{ml}$. On average, they cultivate the rice area of $2 \mathrm{ha}$ and sell their product at the price of 5,800 VND/kg. Most farmers interviewed have much experience in pesticide use (over 19 years), but their education level is low (On average 7 years). Less than half of farmers ( 44 percent) declared that they at least attended short trainings or meetings given by pesticide companies or governmental extension staff, while over half of them could know and recognize pet insect ( 60 percent) and think that pests and diseases are gradually increasing over time (59 percent).

Table 3: Descriptive statistics of variables in the demand function of pesticides

\begin{tabular}{lllll}
\hline Variables & Mean & S.D. & Min. & Max. \\
\hline Amount of pesticides $\left(\mathrm{ml} / 1000 \mathrm{~m}^{2}\right)$ & 449.07 & 108.74 & 192.59 & 855.48 \\
Pesticide price $(\mathrm{VND} / \mathrm{ml})$ & $1,003.89$ & 307.23 & 580.83 & $3,284.13$ \\
Output price $(\mathrm{VND} / \mathrm{kg})$ & $5,795.63$ & 282.07 & $5,100.00$ & $6,666.67$ \\
Area $\left(1000 \mathrm{~m}^{2}\right)$ & 20.58 & 16.92 & 3 & 91 \\
Education level (years) & 7.00 & 3.24 & 1 & 16 \\
Experience of pesticide use (years) & 19.16 & 7.70 & 3 & 33 \\
Knowledge about insects and diseases (Scores) & 3.11 & 0.56 & 1.91 & 4 \\
Knowledge about natural enemies (1=yes, 0=no) & 0.60 & 0.49 & 0 & 1 \\
Attending training (1=yes, 0=no) & 0.44 & 0.50 & 0 & 1 \\
Perception on increasing insects and diseases (1=yes, & 0.59 & 0.50 & 0 & 1 \\
$0=$ (1=) & & & \\
\hline
\end{tabular}

Note: The score of knowledge is estimated by averaging the sum of scores. Rice farmers were asked whether or not they recognize insects and diseases usually occurred in the rice production. The score is equal to 1 if they answer that 'I don't know', equal to 2 if they answer 'I little know', equal to 3 if they answer 'I know', and equal to 4 if they reply 'I know well'.

Source: Own estimates; data appendix available from authors. 
Table 4 shows the OLS regression results of the pesticide demand function. The model is statistically significant because the computed $F$ statistic of 14.34 is more than the critical $F(9,70)$ value of 2.67 at the level of at the level of 1 percent. The estimated R-squared is equal to nearly 0.65 , revealing the 65 percent change of pesticide use possibly explained by the independent variables in the model.

\section{Table 4: The OLS regression of pesticide demand of rice farmers}

\begin{tabular}{lcl}
\hline Variables & Coefficient & Standard Error \\
\hline Pesticide price in natural logarithm & $-0.291^{* * *}$ & 0.091 \\
Output price in natural logarithm & $0.854^{* *}$ & 0.372 \\
Area in natural logarithm & 0.039 & 0.024 \\
Education level in natural logarithm & -0.025 & 0.030 \\
Experience of pesticide use in natural logarithm & -0.026 & 0.036 \\
Knowledge about insects and diseases & 0.044 & 0.034 \\
Knowledge about natural enemies & $-0.082^{* *}$ & 0.040 \\
Attending training & $-0.073^{*}$ & 0.040 \\
Perception on increasing insects and diseases & $0.280^{* * *}$ & 0.039 \\
Constant & 0.473 & 3.362 \\
R-squared & 0.648 & \\
F-statistic model & $14.34^{* * *}$ & \\
Observation (N) & 80 & \\
\hline
\end{tabular}

Notes: ${ }^{* * *}, * *, *$ indicate statistical significance at the $0.01,0.05$ and 0.1 level respectively

Source: Own estimates; data appendix available from authors.

The results show that there is no multicollinearity in the independent variables of pesticide demand function because the correlations of these independent variables estimated by using the correlation matrix are less than 70 percent (Khai and Yabe, 2013; 2014). The study also applies the test of Breusch-Pagan ${ }^{1}$ to check $^{2}$ whether or not the present of heteroscedasticity in the regression analysis is (Khai and Yabe, 2012). Since the estimated $L M$ value of 0.30 is less than the critical $\chi_{9}^{2}$ of 21.67 at the level of 1 percent, the null hypothesis homoscedasticity is accepted and so the problem of heteroscedasticity is absent in the analysis. The coefficient of Pesticide price variable is significantly negative at the level of 1 percent, revealing that an increase in pesticide price reduces its demand, consistent with the expectation. The study also indicates that the output price significantly increases pesticide use at the 5 percent significant level. An increase in the output price would induce them to use increased pesticides in an attempt to boost their crop yield levels and to generate higher revenue. These results are similar to the other findings by Rahman (2003). Consistent with the study by 0 o et al. (2012), the coefficients of Knowledge about natural enemies and Attending training variable are significantly negatively associated with pesticide use, indicating that farmers who attend any training courses or are able to recognize pet insect control tend to use fewer pesticides. In accordance with expectation, those who consider the increasing trend of insects and diseases use more pesticides because the coefficient of Perception on increasing insects and diseases is statistically significantly positive at the level of 1 percent.

\section{Conclusion}

This paper investigated rice farmers' perceptions and pesticide use practices. Pesticides play an important role in rice production for rice farmers in the Mekong Delta, Vietnam. Farmer believed that pesticides were one of the most essential components of economic safety against the uncertainties of rice production in the region. This perception could be a reasonable explanation why most farmers seem to accept the primacy of economic risk without pesticide use over possible health risks. The results showed that farmers' knowledge about the natural enemies and IPM programs is limited. In the 80 farmers interviewed, up to $65 \%$ do not know about any integrated pest management programs. Rice production depends entirely on pesticides.

\footnotetext{
${ }^{1}$ Breusch-Pagan test for heterscedasticity: $L M=n R^{2} \sim \chi_{k}^{2}$, where $n$ is the number of observations; R2 is the RSquaredof $\left|\hat{u}_{i}\right|=\tilde{\delta}_{0}+\tilde{\delta}_{1} X_{1 i}+\tilde{\delta}_{2} X_{2 i}+\cdots++\tilde{\delta}_{k} X_{k i}++\tilde{v}_{i}$; and $k$ is the number of restricted factors.
} 
Farmers have no choice but to use pesticides for pest management. Although farmers were aware of the dangers of pesticides and the benefits of protective things during spraying, in fact their pesticide usage was completely contrary to perception. Most farmers did not wear protective clothing while spraying and obeyed exactly the isolation time after spraying. Thus, about $30 \%$ of households interviewed were found to have symptoms of poisoning, allergies such as vomiting, headache, shortness of breath, itching.

The study also performed that the information associated with pest management and the supports of extension services were provided very weakly. Rice farmers mainly received information on pest management from pesticide sellers (72.5 percent), own experiences (61.3 percent) and from other farmers (40 percent). The propagation and dissemination of information on pest management and safety in the use of pesticides should be promoted and encouraged in the strong manner. The study revealed that increased the price of output or perception of increasing insects and diseases over time significantly positively affected pesticides, while farmers who could recognize natural enemies or have already attended any short training courses in the past have tended to use less pesticides. Moreover, since the activities of the existing agricultural extension networks have mainly focused on promoting modern technology adoption and use of modern inputs without mentioning harmful impacts, farmers' awareness of the harmful effects of pesticides is not very strong. Therefore, a priority policy option should be to utilize and incorporate the existing agricultural extension network and pesticide companies to operate short training courses for educating farmers to understand the harmful effects of pesticide use and to train them in proper handling and management practices. These activities could be useful to decrease the adverse impacts of increased pesticide usage as a result of increased adoption of modern agricultural technology or diversified cropping systems.

Conflicts of interest: The author declares no conflict of interest.

\section{References}

Berg, H. (2001). Pesticide use in rice and rice-fish farms in the Mekong Delta, Vietnam. Crop Protection, 20(10), 897-905. doi: Doi 10.1016/S0261-2194(01)00039-4

Bhanti, M., Shukla, G. \& Taneja, A. (2004). Contamination levels of organochlorine pesticides and farmers' knowledge, perception, practices in rural India: A case study. Bulletin of Environmental Contamination and Toxicology, 73(5), 787-793. doi: DOI 10.1007/s00128-004-0496-8

Khai, H. \& Yabe, M. (2013). Impact of Industrial Water Pollution on Rice Production in Vietnam. In N. W. T. Quinn (Ed.), International Perspectives on Water Quality Management and Pollution Control (pp. 61 85). Croatia: InTech Publisher.

Khai, H. V. \& Yabe, M. (2012). Rice Yield Loss Due to Industrial Pollution in Vietnam. Journal of US-China Public Administration, 9(3), 248-256.

Khai, H. V. \& Yabe, M. (2014). The demand of urban residents for the biodiversity conservation in U Minh Thuong National Park, Vietnam. Agricultural and Food Economics, 2(1), 10.

Ngowi, A., Mbise, T. J., Ijani, A. S. M., London, L. \& Ajayi, O. C. (2007). Smallholder vegetable farmers in Northern Tanzania: Pesticides use practices, perceptions, cost and health effects. Crop Protection, 26(11), 1617-1624. doi: DOI 10.1016/j.cropro.2007.01.008

Ntow, W. J., Gijzen, H. J., Kelderman, P. \& Drechsel, P. (2006). Farmer perceptions and pesticide use practices in vegetable production in Ghana. Pest Management Science, 62(4), 356-365. doi: Doi 10.1002/Ps.1178

Oo, M. L., Yabe, M. \& Khai, H. V. (2012). Farmers' Perception, Knowledge and Pesticide Usage Practices: A Case Study of Tomato Production in Inlay Lake, Myanmar. Journal of the Faculty of Agriculture Kyushu University, 57(1), 327-331.

Rahman, S. (2003). Farm-level pesticide use in Bangladesh: determinants and awareness. Agriculture Ecosystems \& Environment, 95(1), 241-252. doi: Pii S0167-8809(02)00089-0

Van Mele, P., Cuc, N. T. T. \& Van Huis, A. (2001). Farmers' knowledge, perceptions and practices in mango pest management in the Mekong Delta, Vietnam. International Journal of Pest Management, 47(1), 7-16. doi: 10.1080/09670870150215559

Waichman, A. V., Eve, E. \& Nina, N. C. D. (2007). Do farmers understand the information displayed on pesticide product labels? A key question to reduce pesticides exposure and risk of poisoning in the Brazilian Amazon. Crop Protection, 26(4), 576-583. doi: DOI 10.1016/j.cropro.2006.05.011. 